\title{
Cranioplasty Using Autologous Bone versus Porous Polyethylene versus Custom-Made Titanium Mesh : A Retrospective Review of 108 Patients
}

\author{
Jun-Ki Kim, M.D., Sang-Bok Lee, M.D., Seo-Yeon Yang, M.D. \\ Department of Neurosurgery, Uijeongbu St. Mary's Hospital, College of Medicine, The Catholic University of Korea, Uijeongbu, Korea
}

Objective : The purpose of this study was to compare the cosmetic outcome and complications after cranioplasty (CP) due to three different implant materials, and analyze the mean implant survival and cumulative survival rate based on these results.

Methods : We reviewed 108 patients retrospectively who underwent CP between January 2014 and November 2016. Autologous bone (AB; 45 patients) and synthetic materials with porous polyethylene (PP; 32 patients) and custom-made 3-dimensional printed titanium mesh (CT; 31 patients) were used as implants.

Results : Regardless of implanted materials, more than $89.8 \%$ of the CP patients were satisfied with the cosmetic outcome. No statistically significant difference was observed among the three groups. The overall postoperative complication rates of each group were $31.1 \%$ in the AB group, $15.6 \%$ in the PP group and $3.2 \%$ in the CT group. The CT group showed lower complication rates compared with $A B$ and PP groups ( $\chi^{2}$-test : $A B$ vs. PP, $p=0.34 ; A B$ vs. $C T, p=0.00 ; P P$ vs. $C T, p=0.03$ ). The $A B$ and PP groups demonstrated a higher post-CP infection rate (11.1\% and 6.3\%) than the CT group (3.2\%). However, no significant difference in the incidence of post-CP infection was observed among the three groups. The PP and CT groups demonstrated a higher mean implant survival time and cumulative survival rate than the $A B$ group at the last follow-up $(p<0.05)$.

Conclusion : In comparison with $\mathrm{AB}$ and PP, cranioplasty with $\mathrm{CT}$ shows benefits in terms of lower post-CP complication, less intraoperative bleeding loss, shorter operation time and in-hospital stay. The PP and CT groups showed higher implant survival time and cumulative survival rate compared with the $A B$ group.

Key Words : Reconstructive surgical procedure · Infection · Bone resorption · Titanium.

\section{INTRODUCTION}

In the last 2 decades, decompressive craniectomy (DC) played an important role in saving neurocritical patients such as those sustaining severe traumatic brain injury (TBI), isch- emic stroke, subarachnoid hemorrhage (SAH), severe intracranial infection and intracranial tumor ${ }^{1,10,11,15,24,28)}$. Patients who underwent DC recovered from the neurocritical condition and subsequent cranioplasty $(\mathrm{CP})$ were needed to reconstruct the skull defect. The main goals of $\mathrm{CP}$ include biome-

- Received : March 5, 2018 •Revised : May 23, 2018 •Accepted : July 28, 2018

- Address for reprints : Sang-Bok Lee, M.D.

Department of Neurosurgery, Uijeongbu St. Mary's Hospital, College of Medicine, The Catholic University of Korea, 271 Cheonbo-ro, Uijeongbu 11765, Korea Tel : +82-31-820-3299, Fax : +82-31-846-3117, E-mail : leesb@catholic.ac.kr

This is an Open Access article distributed under the terms of the Creative Commons Attribution Non-Commercial License (http://creativecommons.org/licenses/by-nc/4.0) which permits unrestricted non-commercial use, distribution, and reproduction in any medium, provided the original work is properly cited. 
chanical protection of the brain as well as cosmetic effect. In addition, it normalizes the intracranial pressure, thus restoring the cerebrospinal fluid dynamics to promote cerebral metabolism ${ }^{8,18,29)}$. In many cases, $\mathrm{CP}$ was performed using autologous bone $(\mathrm{AB})$, which was obtained at the time of $\mathrm{DC}$. $\mathrm{AB}$ is inexpensive and biocompatible, without any risk of disease transmission and perfectly fits the skull defect. However, it is often excluded because $A B$ is associated with a high failure rate due to infection or bone flap resorption (BFR) $)^{9,13,16,22)}$. Several materials have been designed to replace $\mathrm{AB}$. Materials including polymethyl-methacrylate, hydroxylapatite, and porous polyethylene (PP) have been introduced as implant materials for CP. These materials are malleable substitutes and require intraoperative molding resulting in increased operation time. Additionally, depending on the surgeon's dexterity, it may result in poor cosmetic outcomes in patients with large defects. Therefore, prefabrication of customized cranioplastic implants has been used to compensate the disadvantages of these malleable materials. The use of prefabricated implants tailored to the patient's defect leads to favorable cosmetic effects as well as shortens the operation time. Custom-made 3-dimensional printed titanium mesh (CT) is a commonly used implant for CP. Titanium is characterized by strength, high biocompatibility, lack of corrosion, biological inertness and satisfactory cosmesis $^{5,19,32,33)}$ and long-term outcome of patients who underwent $\mathrm{CP}$ with titanium mesh is more favorable compared with patients treated with $\mathrm{CP}$ using $\mathrm{AB}^{32)}$.

The aim of this retrospective study was to compare the clinical outcome and complications related to three different implant materials. In addition, we analyzed the mean implant survival time and cumulative survival rate associated with the implant materials.

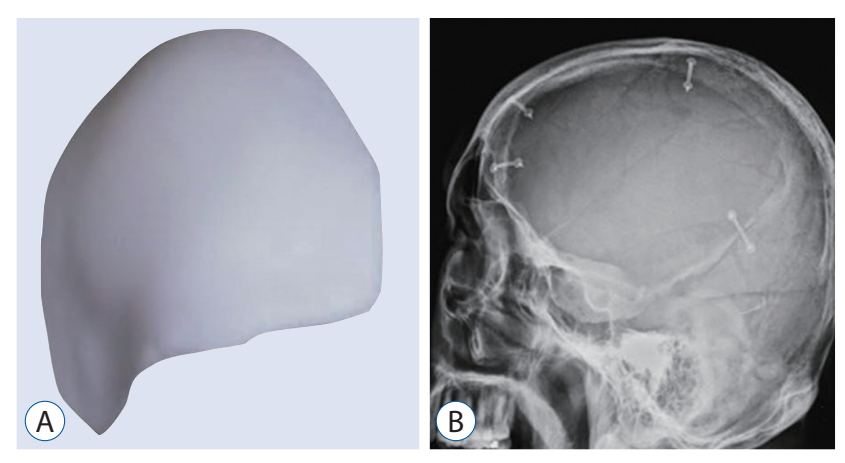

Fig. 1. The Medpor (porous polyethylene) implant (A). Post-operative lateral skull radiograph showing radiolucent Medpor implant (B).

\section{MATERIALS AND METHODS}

From January 2014 to December 2016, 147 CP procedures were performed in 118 consecutive patients with three different materials. This study was approved by the institutional review board of The Catholic University of Korea (IRB No. UC18RES10122). After institutional review board approval was obtained, we retrospectively analyzed the medical records of 108 of these patients, who were followed up for at least 1 year from CP. The mean age was 51 years, ranging from 18 to 83 years. According to the implant material, these patients were classified into three groups : AB group, PP (Fig. 1) group, and CT (Fig. 2) group. All surgeries were performed by two neurosurgeons in our single institution. We reviewed the parameters including age, sex, indications for DC, site of DC (unilateral or bilateral), the presence of multiple fractures within the bone flap, implant material, time interval between the DC and CP (days), craniectomy size $\left(\mathrm{mm}^{3}\right)$, intraoperative blood loss $(\mathrm{mL})$, operative time and duration of hospital stay (days). Based on the cause of DC, the patients were divided into two groups : 1) TBI including acute subdural hemorrhage, epidural hemorrhage and traumatic intracranial hemorrhage (T-ICH); and 2) cerebrovascular accidents (CVA) including major infarction, subarachnoid hemorrhage and spontaneous ICH. Patients who were less than 18 years and underwent DC at other hospitals were excluded. Patients who underwent DC due to infection and brain tumor were also excluded because of the small number of patients. Based on timing, CP was classified into early CP ( $<90$ days after DC) and late CP ( $\geq 90$ days after DC). Timing of the CP depends on the surgeon's decision according to the patient's condition. The craniectomy size was measured on a Picture Archiving and Communication System
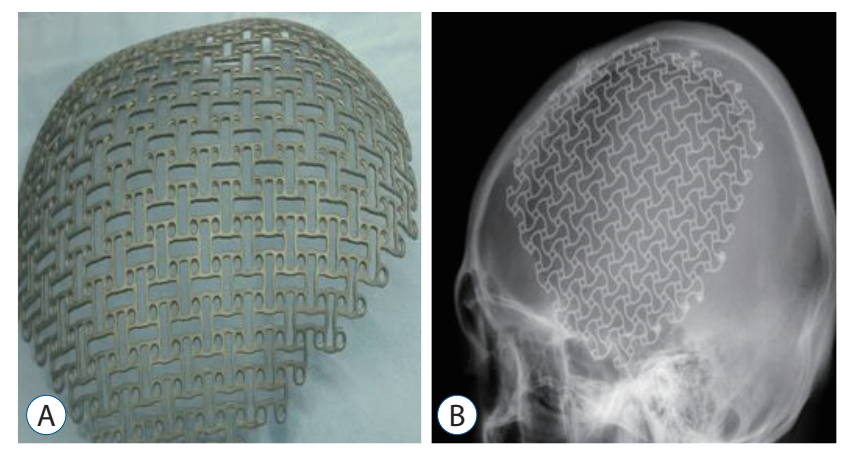

Fig. 2. The 3D design for printing custom-made titanium implant (A). Titanium mesh was placed on the defect site with screw fixation (B). 
work station (Marosis; Marotech, Seoul, Korea) using its freehand region of interest measurement tools. Based on the size, craniectomy was categorized into large $\left(\geq 100 \mathrm{~mm}^{2}\right)$ and small $\left(<100 \mathrm{~mm}^{2}\right)$ groups. Based on the number of bone fragments, the groups were divided into those with $0-1$ bone piece and 2 or more bone pieces. The bone flap was obtained at the time of DC, and was refrigerated below $-80^{\circ} \mathrm{C}$. Before surgery, bone biopsy of $\mathrm{AB}$ was not performed.

The criteria for the selection of implants were as follows : 1) use of $\mathrm{AB}$ for $\mathrm{CP}$ in most patients if possible; 2) if $\mathrm{AB}$ was contraindicated because of contamination at the timing of trauma (e.g., trauma with exposed bone or comminuted fracture), use of synthetic materials; and 3) between two synthetic materials, selection was made by patients or their guidance with help of detailed explanation of the two synthetic materials.

\section{Porous polyethylene implant (Medpor, Porex Surgical, Inc., Newnan, GA, USA)}

Porous polyethylene is a biocompatible, flexible and contourable material for CP. Porous polyethylene implants provide strength and protective effect similar to the AB flap. In contrast to polymethyl-methacrylate, this material is porous and allows new bone and fibrous tissue infiltration. During surgery, it requires intraoperative molding.

\section{Custom-made three-dimensional printed tita- nium mesh (Rain maker, Seoul, Korea)}

Digital Imaging and Communications in Medicine (DICOM) data were obtained from a high-resolution helical multi-slice CT scan of the patient's head (Philips Brilliance 128 Slice CT; Philips Healthcare, Best, The Netherlands). Subsequently, the DICOM data were converted to 3D images, and a prototype model of the skull and defect was created based on these images. Once 3D prototype of skull was deemed a good fit, a prototype mold was created to manufacture the plate. The titanium plate was $0.6 \mathrm{~mm}$ to $10 \mathrm{~mm}$ thick, depending on the location. This plate was molded and try-fitted according to the contour with the skull prototype. The plate was subjected to steam sterilization before surgery.

\section{Evaluation of clinical outcomes and complica- tions}

The clinical outcome was evaluated by assessing the cos- metic outcome after CP. Cosmetic outcomes were obtained from patients or patient's caregivers who visited the out-patient clinic during the follow-up periods. Cosmetic outcome was categorized into three categories : 1) complete satisfaction, satisfied with appearance; 2) partial satisfaction, satisfied with appearance but not ideal (e.g., temporal dimple); and 3) unsatisfactory, unsatisfied with appearance or requiring a revision surgery.

Complications were retrospectively reviewed according to the medical records of each patient. Complications included post-CP infection, BFR, wound dehiscence, postoperative hemorrhage and implant displacement. Post-CP infection was by confirmed by elevated C-reactive protein and abnormal increase in fluid collection revealed in post-operative enhanced computed tomography or magnetic resonance scan.

BFR was defined as the flap with complete lysis through both sides of the bone flap (Fig. 3). Therefore, revision surgery was required because cerebral protection was significantly compromised. BFR was evaluated using computed tomography scan with bone setting (W/L 2500/500 HU). Postoperative hemorrhage was defined as ipsilateral symptomatic hemorrhage on immediately postoperative computed tomography scan after CP warranting reoperation. Wound dehiscence was defined by the rupture or splitting of a previously closed surgical site, resulting in exposure of the implant.

The mean implant survival time and the cumulative implant survival rate were used to assess the survival rate of remaining primary implant during the follow-up periods. Following the diagnosis of post-CP infection, BFR or implant

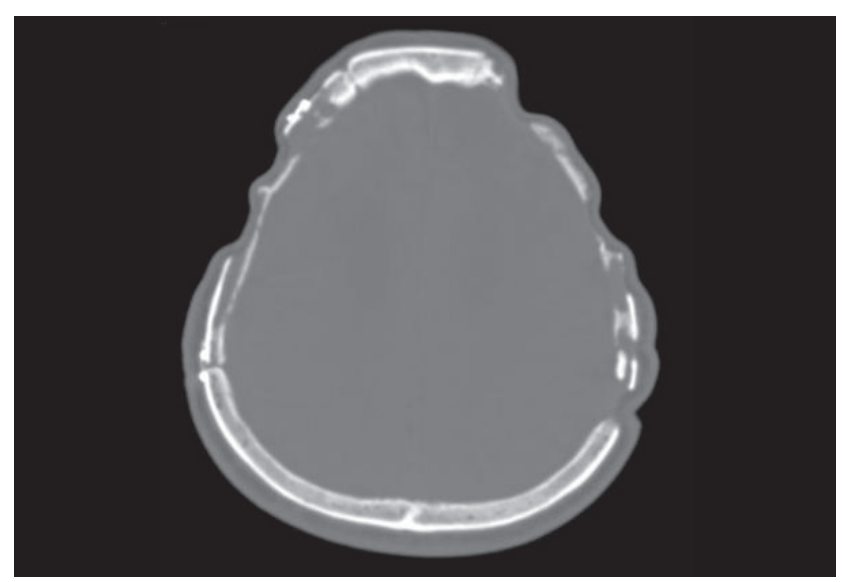

Fig. 3. Computed tomographic image of bone flap resorption demonstrating complete lysis of both inner and outer tables in the bilateral skull. 
displacement or revision surgery based on the aforementioned conditions as the end point, the mean implant survival times and the cumulative implant survival rates were analyzed using Kaplan-Meier product-limit method.

\section{Statistical analysis}

Quantitative variables were expressed as mean \pm standard deviation. One-way analysis of variance (ANOVA) was used to compare the continuous variables in the three different groups. Unpaired t-test for continuous variables and chisquare test for categorical variables were used. The risk factors for post-CP infection and BFR were analyzed via univariate analysis. The risk factors for infection and BFR were assessed using logistic regression analysis. Parameters with $p$ value $<0.1$ in the univariate analysis were included in the logistic regression. The mean implant survival time and the cumulative implant survival rate were estimated using the Kaplan-Meier product-limit method. Confidence interval (CI) for KaplanMeier method was set at 95\%. The log-rank test was used to evaluate differences between survival time curves of the three different materials. The SPSS software (version 15.0, 2006; SPSS, Inc., Chicago, IL, USA) was used, and the probability value $<0.05$ indicated statistical significance.

Table 1. Characteristics of 108 patients of cranioplasty

\begin{tabular}{|c|c|c|c|c|}
\hline & $A B$ group $(n=45)$ & PP group $(n=32)$ & CT group $(n=31)$ & $p$-value* \\
\hline Mean age (at the time of cranioplasty) & $50.9 \pm 16.7$ & $52.9 \pm 13.4$ & $51.1 \pm 14.8$ & 0.73 \\
\hline Sex ratio (M/F) & $37 / 8$ & $10 / 22$ & $18 / 13$ & 0.12 \\
\hline Implant size $\left(\mathrm{cm}^{2}\right)$ & & & & 0.5 \\
\hline$<100$ & $19(42.2)$ & $12(37.5)$ & $9(29.0)$ & \\
\hline$\geq 100$ & $26(57.8)$ & $20(62.5)$ & $22(71.0)$ & \\
\hline Preoperative neurological status (GCS score) & & & & 0.62 \\
\hline$\geq 13$ & $17(37.8)$ & $12(37.5)$ & $13(41.9)$ & \\
\hline$\geq 9$ & $20(44.4)$ & $17(53.1)$ & $15(48.4)$ & \\
\hline$\leq 8$ & $8(17.8)$ & $3(9.4)$ & $3(9.7)$ & \\
\hline Reason for primary operation & & & & 0.17 \\
\hline \multicolumn{5}{|l|}{ Trauma } \\
\hline Subdural hemorrhage & $19(67.9)$ & $7(53.8)$ & $10(58.8)$ & \\
\hline Contusion (traumatic hemorrhage) & $6(21.4)$ & $4(30.8)$ & $5(29.4)$ & \\
\hline Epidural hemorrhage & $3(10.7)$ & $2(15.4)$ & $2(11.8)$ & \\
\hline \multicolumn{5}{|l|}{ Cerebrovascular accident } \\
\hline Subarachnoid hemorrhage & $3(17.6)$ & $12(63.2)$ & $8(57.1)$ & \\
\hline Spontaneous ICH & $9(52.9)$ & $5(26.3)$ & $2(14.3)$ & \\
\hline Major infarction & $5(29.5)$ & $2(10.5)$ & $4(28.6)$ & \\
\hline Timing of the cranioplasty & & & & 0.09 \\
\hline Early surgery $(<90)$ & $30(66.7)$ & $19(59.4)$ & $26(83.9)$ & \\
\hline Late surgery $(\geq 90)$ & $15(33.3)$ & $13(40.6)$ & $5(16.1)$ & \\
\hline Site of DC & & & & 0.29 \\
\hline Unilateral craniectomy & $38(84.4)$ & $25(78.1)$ & $28(90.3)$ & \\
\hline Bilateral craniectomy & $7(15.6)$ & $7(21.9)$ & $3(9.7)$ & \\
\hline Cost of implant ${ }^{\dagger}$ (dollars) & 0 & 2040 & 4100 & \\
\hline Mean follow up periods (months) & $28.8 \pm 9.4$ & $29.1 \pm 8.6$ & $26.3 \pm 8.3$ & 0.38 \\
\hline
\end{tabular}

Values are presented as mean \pm standard deviation or number (\%). *All values were generated by one-way ANOVA or chi-square test. ${ }^{\dagger}$ Presented in US dollars. AB : autologous bone, PP : porous polyethylene, CT : custom-made 3-dimensional printed titanium mesh, M : male, F : female, GCS : Glasgow coma scale, ICH : intracranial hemorrhage, DC : decompressive craniectomy 


\section{RESULTS}

Between January 2014 and November 2016, 108 patients underwent $125 \mathrm{CP}$ with three different materials at our institution. The $\mathrm{CP}$ with $\mathrm{AB}$ was conducted at 52 sites in 45 patients; $\mathrm{CP}$ with PP was performed at 39 sites in 32 patients; and CP with CT was performed at 34 sites in 31 patients. The mean clinical and radiological follow-up was 28.1 45.1 months (range, 12-45). The patients included 77 males and 31 females. The mean age of patients at the time of CP was $51.6 \pm 14.9$ years (range, 19-83). The causes of DC were as follows : trauma (58 patients, 53.7\%) and CVA (50 patients, 46.3\%). The demographic data of 108 patients are summarized in Table 1, and the three groups were well matched at baseline. No statistically significant difference in demographics was observed among the groups.

\section{Comparison of cosmetic outcomes, operation time, bleeding loss and hospital stay}

The cosmetic outcomes in the $\mathrm{AB}$ group including 18 pa- tients were completely satisfactory; partially satisfactory in 22 patients, and unsatisfactory in five patients. The corresponding cosmetic outcomes in the PP group were 12,16 , and 4, respectively, and those in the CT group were 15, 14, and 2, respectively. No significant differences were observed between three groups ( $\chi^{2}$-test : $\mathrm{AB}$ vs. $\mathrm{PP}, p=0.75$; $\mathrm{AB}$ vs. CT, $p=0.35$; PP vs. CT, $p=0.56)$.

Duration of hospitalization and intra-operative parameters were also evaluated. The CT group demonstrated the shortest in-hospital stay compared with the other two groups (one-way ANOVA with post-hoc analysis, $p=0.00$ ). Regarding the intraoperative parameters, patients in the CT group experienced the shorter operation time and less blood loss among the three groups (one-way ANOVA with post-hoc analysis, $p=0.00$ and $p=0.00)$. Clinical outcomes are summarized in Table 2 .

\section{Complications}

During the follow-up periods, overall postoperative complications occurred in $20(18.5 \%)$ of 108 patients (14 patients [31.1\%] in AB group, five patients [15.6\%] in PP group, and

Table 2. Outcomes of the patients who underwent primary cranioplasty according to the materials

\begin{tabular}{|c|c|c|c|c|}
\hline & $A B$ group $(n=45)$ & PP group $(n=32)$ & CT group $(n=31)$ & $p$-value* \\
\hline Time interval from DC to CP (days) & $80.7 \pm 58.6$ & $87 \pm 53.7$ & $74.6 \pm 61.5$ & 0.84 \\
\hline Postoperative neurologic outcome (GCS) & & & & 0.74 \\
\hline$\geq 13$ & $19(42.2)$ & $13(40.6)$ & $15(48.4)$ & \\
\hline$\geq 9$ & $18(40)$ & $16(50)$ & $14(45.2)$ & \\
\hline$\leq 8$ & $8(17.8)$ & $3(9.4)$ & $2(6.4)$ & \\
\hline Cosmetic outcome & & & & 0.5 \\
\hline Completely satisfaction & $18(40)$ & $12(37.5)$ & $15(48.4)$ & \\
\hline Partial satisfaction & $22(48.9)$ & $16(50)$ & $14(45.2)$ & \\
\hline Unsatisfactory & $5(11.1)$ & $4(12.5)$ & $2(6.4)$ & \\
\hline Postoperative overall complications & $14(31.1)$ & $5(15.6)$ & $1(3.2)$ & $0.00^{\dagger}$ \\
\hline Infection & $5(11.1)$ & $2(6.3)$ & $1(3.2)$ & \\
\hline Bone flap resorption & $5(11.1)$ & 0 & 0 & \\
\hline Wound dehiscence & $2(4.4)$ & $2(6.3)$ & 0 & \\
\hline Implant displacement & $2(4.4)$ & 0 & 0 & \\
\hline Postoperative hemorrhage & 0 & $1(3.1)$ & 0 & \\
\hline Mean operation time (minutes) & $188.3 \pm 53.0$ & $201.2 \pm 55.5$ & $165.9 \pm 35.1$ & $0.00^{\dagger}$ \\
\hline Blood loss during the operation (mL) & $247.4 \pm 122.2$ & $283.2 \pm 195.8$ & $188.7 \pm 11.8$ & $0.00^{\dagger}$ \\
\hline Average hospital stay (day) & $16.7 \pm 7.8$ & $15.1 \pm 5.8$ & $12.9 \pm 3.6$ & $0.01^{\dagger}$ \\
\hline
\end{tabular}

Values are presented as mean \pm standard deviation or number (\%). *All values were generated by one-way ANOVA with post hoc analysis or chi-square test. 'Statistical significance. AB : autologous bone, PP : porous polyethylene, CT : custom-made 3-dimensional printed titanium mesh 
one patient [3.2\%] in CT group). The CT group showed lower overall complication rates compared with $\mathrm{AB}$ and $\mathrm{PP}$ groups ( $\chi^{2}$-test $: \mathrm{AB}$ vs. PP, $p=0.34 ; \mathrm{AB}$ vs. $\mathrm{CT}, p=0.00$; PP vs. $\mathrm{CT}$, $p=0.03$ ). Complications are summarized in Table 2.

\section{Factors affecting post-CP infection}

A total of eight cases (7.4\%) of post CP-infections were observed among the 108 patients. They include five post CP- infections in the $\mathrm{AB}$ group (11.1\%), two post CP-infections in

Table 3. Univariate analysis comparing the no-infection and the infection groups after cranioplasty

\begin{tabular}{|c|c|c|c|}
\hline Clinical parameter & $\begin{array}{c}\text { No } \\
\text { infection } \\
(n=100)\end{array}$ & $\begin{array}{l}\text { Infection } \\
\quad(n=8)\end{array}$ & $p$-value* \\
\hline Age (years) & & & 0.43 \\
\hline$\geq 60$ & $71(91.0)$ & $7(9.0)$ & \\
\hline$<60$ & $29(96.7)$ & $1(3.3)$ & \\
\hline Sex & & & 0.58 \\
\hline Male & $71(92.2)$ & $6(7.8)$ & \\
\hline Female & $29(93.5)$ & $2(6.5)$ & \\
\hline Timing of the cranioplasty & & & 0.69 \\
\hline Early surgery $(<90)$ & $70(93.3)$ & $5(6.7)$ & \\
\hline Late surgery $(\geq 90)$ & $30(90.9)$ & $3(9.1)$ & \\
\hline Location of carniectomy & & & 0.66 \\
\hline Unilateral & $83(91.2)$ & $8(8.8)$ & \\
\hline Bilateral & $17(100.0)$ & 0 & \\
\hline Shunt procedure & & & 0.6 \\
\hline Undo & $51(87.9)$ & $7(12.1)$ & \\
\hline Do & $49(98.0)$ & $1(2.0)$ & \\
\hline Cause of craniectomy & & & 0.06 \\
\hline Trauma & $51(87.9)$ & $7(12.1)$ & \\
\hline Vascular accident & $49(98.0)$ & $1(2.0)$ & \\
\hline Implants & & & 0.41 \\
\hline Autologous bone & $40(88.9)$ & $5(11.1)$ & \\
\hline Porous polyethylene & $30(93.8)$ & $2(6.3)$ & \\
\hline Titanium & $30(96.8)$ & $1(3.2)$ & \\
\hline Bone size & & & 0.62 \\
\hline Small $\left(<100 \mathrm{~cm}^{2}\right)$ & $37(92.5)$ & $3(7.5)$ & \\
\hline Large $\left(\geq 100 \mathrm{~cm}^{2}\right)$ & $63(92.6)$ & $5(7.4)$ & \\
\hline Postoperative wound dehiscence & & & $0.00^{\dagger}$ \\
\hline No & $99(95.2)$ & $5(4.8)$ & \\
\hline Yes & $1(25.0)$ & $3(75.0)$ & \\
\hline Operation time (minutes) & $184.6 \pm 48.3$ & $241.7 \pm 55.6$ & 0.07 \\
\hline
\end{tabular}

*All values were calculated with chi-square test. ${ }^{\dagger}$ Statistically significant the PP group (6.3\%), and one post-CP infection in the CT group (3.2\%). All infected implants were removed. Patient groups without post-CP infection were compared with those who were diagnosed with post-CP infection (Table 3). Wound dehiscence ( $75 \%$ vs. $4.8 \%, \chi^{2}$-test; $p=0.00$ ) was a significant risk factor only for post-CP infection. The type of implants and timing of the surgery were not associated with a higher

Table 4. Logistical regression analyzing the factor affecting the occurrence of the post-CP infection

\begin{tabular}{lcc}
\hline Clinical parameters & OR $(95 \% \mathrm{CI})$ & $\boldsymbol{p}$-value \\
\hline Cause of craniectomy & $0.4(0.08-1.05)$ & 0.37 \\
Wound dehiscence & $1.3(0.98-1.52)$ & $0.00^{*}$ \\
Operation time & $0.8(0.44-1.55)$ & 0.68 \\
\hline
\end{tabular}

*Statistical significance. CP : cranioplasty, OR : odds ratio, Cl : confidence interval

Table 5. Characteristics of the study group stratified by occurrence of BFR in univariate analysis

\begin{tabular}{|c|c|c|c|}
\hline Clinical parameter & $\begin{array}{l}\text { No BFR } \\
(n=40)\end{array}$ & BFR $(n=5)$ & $p$-value* \\
\hline Age (years) & & & 0.31 \\
\hline$\geq 60$ & $30(85.3)$ & $5(14.7)$ & \\
\hline$<60$ & $10(100.0)$ & 0 & \\
\hline Sex & & & 0.64 \\
\hline Male & $33(89.2)$ & $4(8.1)$ & \\
\hline Female & $7(87.5)$ & $1(12.5)$ & \\
\hline Timing of the cranioplasty & & & 0.69 \\
\hline Early surgery $(>90)$ & $24(88.9)$ & $3(11.1)$ & \\
\hline Late surgery ( $\geq 90)$ & $16(88.9)$ & $2(11.1)$ & \\
\hline Cause of craniectomy & & & 0.63 \\
\hline Trauma & $25(89.3)$ & $3(10.7)$ & \\
\hline Vascular accident & $15(88.2)$ & $2(11.8)$ & \\
\hline Bone size & & & 0.17 \\
\hline Small $\left(<100 \mathrm{~cm}^{2}\right)$ & $18(94.7)$ & $1(5.3)$ & \\
\hline Large $\left(\geq 100 \mathrm{~cm}^{2}\right)$ & $22(84.6)$ & $4(15.4)$ & \\
\hline Site of the craniectomy & & & 0.58 \\
\hline Unilateral & $34(89.5)$ & $4(10.5)$ & \\
\hline Bilateral & $6(85.7)$ & $1(14.3)$ & \\
\hline Number of bone fragment & & & $0.01^{\dagger}$ \\
\hline 0-1 piece & $32(97.0)$ & $1(3.0)$ & \\
\hline$>2$ pieces & $8(66.7)$ & $4(33.3)$ & \\
\hline
\end{tabular}

Values are presented as number (\%). *All values were generated by chisquare test. ${ }^{\dagger}$ Statistical significance. BFR : bone flap resorption 
infection rate after $\mathrm{CP}$. The cause of DC and operation time trended toward statistical significance $\left(\chi^{2}\right.$-test, $p=0.07$; unpaired t-test, $p=0.07)$. Logistic regression analysis demonstrated that wound dehiscence $(p=0.00)$ was an independent risk factor for post-CP infections. Patients with wound dehiscence had a 1.3-fold increased risk of complication (odds ratio [OR], 1.3; 95\% CI, 0.9-1.5) compared with patients without wound dehiscence (Table 4).

\section{BFR}

Among the 45 patients included in the $\mathrm{AB}$ group, BFR occurred in five patients (11.1\%). No implant lysis was observed in PP and CT groups during the follow-up. We compared the patient groups without BFR, with those who showed BFR following CP (Table 5). Among the parameters evaluated, multiple skull fractures involving more than two pieces was the only risk factor for BFR. In a logistic regression analysis with BFR as the dependent variables, multiple skull fracture (OR, 2.3; 95\% CI, 2.18-7.51; $p=0.00$ ) was associated with a significantly higher risk for BFR.

\section{Implant survival analysis}

The mean implant survival in AB, PP, and CT groups was 35.1

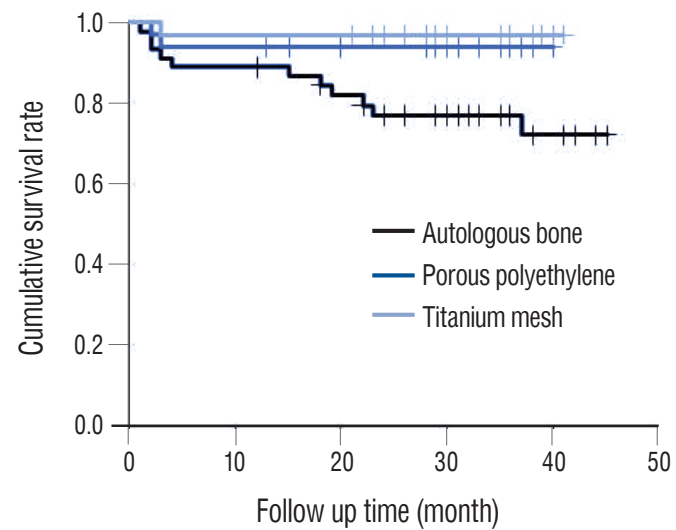

\begin{tabular}{rllllll}
\multicolumn{7}{c}{ Number at risk } \\
Autologous bone & 45 & 40 & 34 & 26 & 14 & 0 \\
Porous polyethylene & 32 & 30 & 28 & 23 & 4 & 0 \\
Titanium mesh & 31 & 30 & 30 & 21 & 2 & 0
\end{tabular}

Fig. 4. Kaplan-Meier plots of the cumulative implant survival rate demonstrated significantly longer implant survival in patients undergoing $C P$ with $\mathrm{PP}$ and $\mathrm{CT}$ compared with those treated with $\mathrm{AB}$ conservatively $(p<0.05)$. CP: cranioplasty, PP : porous polyethylene, $\mathrm{CT}$ : custom-made 3-dimensional printed titanium mesh, $\mathrm{AB}$ : autologous bone. \pm 2.3 months, $37.6 \pm 1.6$ months, and $39.7 \pm 1.2$ months, respectively. Patients who underwent $\mathrm{CP}$ with $\mathrm{PP}$ and $\mathrm{CT}$ showed significantly longer implant survival than those treated with $\mathrm{AB}$ (AB vs. PP, $p=0.03 ; \mathrm{AB}$ vs. $\mathrm{CT}, p=0.00)$. However, no statistically significant difference was observed between CT and PP groups $(p=0.20)$. The cumulative implant survival rates at the last follow-up were $75.3 \%$ for $\mathrm{AB}$ (95\% CI, $63.3 \%$ to $97.8 \%$ ), $93.8 \%$ for the PP (95\% CI, $93.8 \%$ to $96.9 \%$ ), and $96.8 \%$ in the CT group (95\% CI, 96.8\%). The CT and PP groups demonstrated higher implant survival time and cumulative implant survival rate than the $A B$ group at last follow-up (Fig. 4).

\section{DISCUSSION}

The main finding of this study was that, during the followup periods, implanted $\mathrm{AB}$ required removal in $26.6 \%$ of the cases because of post-CP infection, BFR and implant displacement $(11.1 \%, 11.1 \%$, and $4.4 \%$, respectively). Survival analysis of $\mathrm{AB}, \mathrm{PP}$, and $\mathrm{CT}$ groups showed that the mean implant survival time and cumulative implant survival rate of $A B$ group were significantly lower than with the remaining two synthetic implant materials. The primary causes for low implant survival rate of $\mathrm{AB}$ group were post- $\mathrm{CP}$ infection and resorption. $\mathrm{AB}$ still remains a gold standard for $\mathrm{CP}$. Nevertheless, $\mathrm{AB}$ has several disadvantages such as high infection rate, BFR and donor site morbidity when using free bone grafts. In order to overcome these disadvantages, various synthetic materials were invented. Porous polyethylene has been used in craniofacial reconstruction with proven safety and stability. However, it requires intraoperative molding and may be result in poor cosmetic outcome in case of large skull defect. Therefore, a prefabricated 3D-printed titanium mesh was selected for comparison in the present study. The computer-aided design of customized cranioplastic implants facilitates precise preoperative evaluation and simulation, shortened operation time, reduced intra-operative blood loss and results in excellent cosmetic results ${ }^{5,20-22,32,33)}$.

\section{Cosmetic outcomes and parameters}

Regardless of the implanted material, the majority of the patients (89.8\%) were satisfied with the cosmetic results. $\mathrm{AB}$ or CT is user-friendly and perfectly matches the skull defect. Nevertheless, no significant differences in cosmetic outcomes 
were observed between the three groups. Unsatisfactory cosmetic outcome is mostly attributed to temporal hollowing resulting in atrophy of frontal and temporalis muscle following initial DC rather than implant material. Additionally, other factors of cosmetic outcome unrelated to implant material include hair length, location of the defect and skin thickness. In the present study, cosmetic outcome was not associated with the implant materials and synthetic materials represent an attractive alternative option comparable to $\mathrm{AB}$.

The CT group showed shorter operation time and less bleeding loss than the other two groups. Theoretically, the parameters should be similar in $\mathrm{AB}$ and $\mathrm{CT}$ groups, due to these implants do not need for intraoperative molding process. It is assumed that the additional operation time and bleeding are caused by differences in timing of surgery between the two groups. In the present study, the number of patients undergoing early $\mathrm{CP}$ in $\mathrm{CT}$ group was higher than in $\mathrm{AB}$ group. The longer the time interval separating DC from $\mathrm{CP}$, the greater is the time needed for dissection of scalp from the dura. Moreover, in case of multiple skull fractures in AB group, the additional operation time corresponds to the time needed for skull fixation with the screw. The additional bleeding loss in the AB group is probably related to the timing of surgery and the longer operation time.

\section{Factors affecting post-CP infection}

Considering the overall infection rate in cranial procedures varying between $1 \%$ and $2 \%$, the overall infection rate of $\mathrm{CP}$ (eight cases, 7.4\%) in this study demonstrated a high infection rate, consistent with other reports ${ }^{14,17)}$. A recent meta-analysis reported lack of significant difference in infection rate between $\mathrm{AB}$ and synthetic materials ${ }^{34)}$. In this study, the CT group showed a lower post-CP infection rate than the $\mathrm{AB}$ and PP groups. We speculated that $\mathrm{AB}$ and PP contain a multilobulated and porous structure, which may induce bacterial proliferation. Additionally, PP required intraoperative molding, leading to increased operation time. In our study, operation time showed a trend towards statistical significance in the incidence of post-CP infection $(p=0.07)$, explaining the higher infection rate associated with $\mathrm{AB}$ and $\mathrm{PP}$ compared with CT.

The timing of CP appears to be an important factor underlying the post-CP infection and is still disputed ${ }^{2,3,6,12,23,31,34)}$. In this study, our results showed that the timing of CP had no effect on the incidence of post-CP infection (early CP, 6.7\% vs. late CP, 9.1\%; $p=0.69$ ). Although we did not statistically confirm that early $\mathrm{CP}$ had a lower infection rate than late $\mathrm{CP}$, we were inclined to perform early CP if subsidence of brain edema was confirmed. Early CP facilitates dissection of the tissue planes easily with reduced intraoperative bleeding and operation time. For patients, they can be rehabilitated earlier and allow an improvement of neurological functions.

In our study, only wound dehiscence was significantly associated with post-CP infections, consistent with studies reported by Riordan and colleagues ${ }^{26)}$. CP patients undergo at least two or more surgical procedures at the same site, resulting in friable soft tissue, skin retraction, thinning and reduction in scalp tensile force ${ }^{25)}$. Therefore, wound healing may be delayed, leading to skin colonization, which increases the risk of post-CP infections ${ }^{4,7)}$. However, due to the small number of patients $(n=108)$ and a retrospective study may not be precise in documenting the degree of wound dehiscence. Therefore, it is difficult to conclude whether the degree of wound dehiscence affects the post-CP infection. Conversely, implant infection during the operation may be a cause of wound dehiscence. Sundseth et al. ${ }^{30)}$ recommend tissue augmentation or tissue expansion of the scalp before CP in pediatric patients to minimize the chance of wound breakdown. Although, this study is small, tissue augmentation before CP is a good preoperative procedure to reduce the incidence of wound dehiscence in specific patients.

\section{BFR}

Among adult patients, the reported incidence of BFR after CP varied from $4 \%$ to as high as $22 \%$ and in pediatric patients, it was as high as $50 \%{ }^{9,13,14,16,27)}$. In this study, five patients (11.1\%) showed BFR suggesting that brain protection is totally compromised. Schuss et al. ${ }^{27)}$ reported that BFR is more frequent in patients with multiple bone fractures than in those without bone fractures. Our study demonstrated that multiple fractures of bone flap were highly associated with BFR. Multiple bone fractures are a critical factor for poor micro-circulation and may inhibit bone healing. In addition, multiple bone fractures heal less due to the difficult approximation of the fragmented bone. These findings suggest that the age of patients who need DC tend to be young patients because they are usually exposed to high energy trauma. Therefore, it is important to select appropriate implant material for CP that is designed to last a lifetime. 


\section{Study limitations}

The major limitations of this present study include the retrospective format and nonrandomized patient groups. The other limitation relates to known or unknown bias such as different surgical indications and surgical techniques and/or lateralization of the trauma patients in this area. Our institution is geographically isolated. Therefore, most patients with severe head trauma were referred to our center. Unless the patients moved to another area, any complications related to CP were included in this study. Therefore, follow-up loss and underreporting of patients' complication are less likely than in similar other studies.

\section{CONCLUSION}

In comparison with $\mathrm{AB}$ and $\mathrm{PP}$ group, $\mathrm{CT}$ group shows benefits in terms of post-CP complication rate, intraoperative bleeding loss, operation time and in-hospital stay. Among the parameters, wound dehiscence and multiple bone fragments were associated with post-CP infection and BFR, respectively.

The survival analysis of synthetic implants showed higher implant survival time and cumulative implant survival rate compared with the $\mathrm{AB}$ group. In order to substantiate these findings, a prospective randomized controlled trial will be required.

\section{CONFLICTS OF INTEREST}

No potential conflict of interest relevant to this article was reported.

\section{INFORMED CONSENT}

This type of study does not require informed consent.

\section{References}

1. Agrawal $\mathrm{D}$, Hussain $\mathrm{N}$ : Decompressive craniectomy in cerebral toxoplasmosis. Eur J Clin Microbiol Infect Dis 24 : 772-773, 2005

2. Archavlis $E$, Carvi $Y$ Nievas $M$ : The impact of timing of cranioplasty in patients with large cranial defects after decompressive hemicraniectomy. Acta Neurochir (Wien) 154 : 1055-1062, 2012

3. Beauchamp KM, Kashuk J, Moore EE, Bolles G, Rabb C, Seinfeld J, et al. : Cranioplasty after postinjury decompressive craniectomy: is timing of the essence? J Trauma 69 : 270-274, 2010

4. Bruce JN, Bruce SS : Preservation of bone flaps in patients with postcraniotomy infections. J Neurosurg 98 : 1203-1207, 2003

5. Cabraja M, Klein M, Lehmann TN : Long-term results following titanium cranioplasty of large skull defects. Neurosurg Focus 26 : E10, 2009

6. Chang V, Hartzfeld P, Langlois M, Mahmood A, Seyfried D : Outcomes of cranial repair after craniectomy. J Neurosurg 112 : 1120-1124, 2010

7. Cronquist $A B$, Jakob K, Lai L, Della Latta P, Larson EL : Relationship between skin microbial counts and surgical site infection after neurosurgery. Clin Infect Dis 33 : 1302-1308, 2001

8. Dujovny M, Aviles A, Agner C, Fernandez P, Charbel FT : Cranioplasty: cosmetic or therapeutic? Surg Neurol 47 : 238-241, 1997

9. Dünisch P, Walter J, Sakr Y, Kalff R, Waschke A, Ewald C : Risk factors of aseptic bone resorption: a study after autologous bone flap reinsertion due to decompressive craniotomy. J Neurosurg 118 : 1141-1147, 2013

10. Ferro JM, Crassard I, Coutinho JM, Canhão P, Barinagarrementeria F, Cucchiara $B$, et al. : Decompressive surgery in cerebrovenous thrombosis: a multicenter registry and a systematic review of individual patient data. Stroke 42 : 2825-2831, 2011

11. Fisher CM, Ojemann RG : Bilateral decompressive craniectomy for worsening coma in acute subarachnoid hemorrhage. Observations in support of the procedure. Surg Neurol $41: 65-74,1994$

12. Gooch MR, Gin GE, Kenning TJ, German JW : Complications of cranioplasty following decompressive craniectomy: analysis of 62 cases. Neurosurg Focus 26 : E9, 2009

13. Grant GA, Jolley M, Ellenbogen RG, Roberts TS, Gruss JR, Loeser JD : Failure of autologous bone-assisted cranioplasty following decompressive craniectomy in children and adolescents. J Neurosurg 100 (2 Suppl Pediatrics) : 163-168, 2004

14. Honeybul S: Complications of decompressive craniectomy for head injury. J Clin Neurosci 17 : 430-435, 2010

15. Honeybul S, Ho KM : How "successful" is calvarial reconstruction using frozen autologous bone? Plast Reconstr Surg 130 : 1110-1117, 2012

16. Honeybul S, Ho KM : Long-term complications of decompressive craniectomy for head injury. J Neurotrauma 28 : 929-935, 2011

17. Honeybul S, Ho KM : The current role of decompressive craniectomy in the management of neurological emergencies. Brain Inj 27 : 979-991, 2013

18. Kim BJ, Hong KS, Park KJ, Park DH, Chung YG, Kang SH : Customized cranioplasty implants using three-dimensional printers and polymethylmethacrylate casting. J Korean Neurosurg Soc 52 : 541-546, 2012

19. Lee SC, Wu CT, Lee ST, Chen PJ : Cranioplasty using polymethyl methacrylate prostheses. J Clin Neurosci 16 : 56-63, 2009

20. Malis LI : Titanium mesh and acrylic cranioplasty. Neurosurgery 25 : 351-355, 1989

21. Marbacher $S$, Andres RH, Fathi AR, Fandino I : Primary reconstruction of open depressed skull fractures with titanium mesh. J Craniofac Surg 
$19: 490-495,2008$

22. Matsuno A, Tanaka H, Iwamuro H, Takanashi S, Miyawaki S, Nakashima $M$, et al. : Analyses of the factors influencing bone graft infection after delayed cranioplasty. Acta Neurochir (Wien) 148 : 535-540; discussion 540, 2006

23. Piedra MP, Nemecek AN, Ragel BT : Timing of cranioplasty after decompressive craniectomy for trauma. Surg Neurol Int $5: 25,2014$

24. Polin RS, Shaffrey ME, Bogaev CA, Tisdale N, Germanson T, Bocchicchio $B$, et al. : Decompressive bifrontal craniectomy in the treatment of severe refractory posttraumatic cerebral edema. Neurosurgery 41 : 8492; discussion 92-94, 1997

25. Reddy S, Khalifian S, Flores JM, Bellamy J, Manson PN, Rodriguez ED, et al. : Clinical outcomes in cranioplasty: risk factors and choice of reconstructive material. Plast Reconstr Surg 133 : 864-873, 2014

26. Riordan MA, Simpson VM, Hall WA : Analysis of factors contributing to infections after cranioplasty: a single-institution retrospective chart review. World Neurosurg 87 : 207-213, 2016

27. Schuss P, Vatter $H$, Oszvald A, Marquardt G, Imöhl L, Seifert $V$, et al. : Bone flap resorption: risk factors for the development of a long-term complication following cranioplasty after decompressive craniectomy. J Neurotrauma 30 : 91-95, 2013

28. Schwab S, Steiner T, Aschoff A, Schwarz S, Steiner HH, Jansen O, et al. : Early hemicraniectomy in patients with complete middle cerebral artery infarction. Stroke 29 : 1888-1893, 1998

29. Segal DH, Oppenheim JS, Murovic JA : Neurological recovery after cranioplasty. Neurosurgery 34 : 729-731; discussion 731, 1994

30. Sundseth J, Sundseth A, Berg-Johnsen J, Sorteberg W, Lindegaard KF : Cranioplasty with autologous cryopreserved bone after decompressive craniectomy: complications and risk factors for developing surgical site infection. Acta Neurochir (Wien) 156 : 805-811; discussion 811, 2014

31. Thavarajah $D$, De Lacy $P$, Hussien $A$, Sugar $A$ : The minimum time for cranioplasty insertion from craniectomy is six months to reduce risk of infection--a case series of 82 patients. Br J Neurosurg 26 : 78-80, 2012

32. Wiggins A, Austerberry R, Morrison D, Ho KM, Honeybul S: Cranioplasty with custom-made titanium plates--14 years experience. Neurosurgery 72 : 248-256; discussion 256, 2013

33. Wind JJ, Ohaegbulam C, Iwamoto FM, Black PM, Park JK : Immediate titanium mesh cranioplasty for treatment of postcraniotomy infections. World Neurosurg 79 : 207.e11-e13, 2013

34. Yadla S, Campbell PG, Chitale R, Maltenfort MG, Jabbour P, Sharan AD : Effect of early surgery, material, and method of flap preservation on cranioplasty infections: a systematic review. Neurosurgery 68 : 11241129; discussion 1130, 2011 